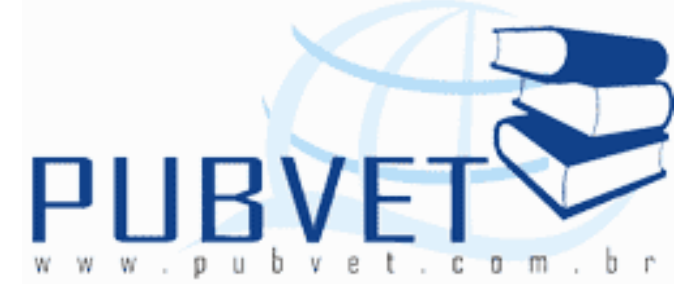

PUBVET, Publicações em Medicina Veterinária e Zootecnia.

\title{
Exigências aminoacídicas para codornas
}

Raquel Pillon Della-Flora ${ }^{1}$; Nelson José Laurino Dionello² ; Ariane Gotuzzo ${ }^{1}$ Jerusa Martins Germano3; Amauri Tavares³; Samantha Alves Azambuja3.

1 Mestrandas em Zootecnia/Bolsistas do CnPq. Departamento de Zootecnia. FAEM/UFPel .Pelotas, RS. Brasil.Processo.

2 Prof.Dr. e Bolsista de produtividade do CNPq. Departamento de Zootecnia. FAEM/UFPel.Pelotas, RS.

3 Alunos do curso de Zootecnia. FAEM/UFPel.Pelotas,RS.

\section{Resumo}

Frente à escassez de informações científicas sobre as exigências aminoacídicas de codornas japonesas (Coturnix coturnix japonica) e européias (Coturnix coturnix coturnix), muitas vezes são utilizadas tabelas de exigências nutricionais como as do NRC (1994) e INRA (1999), pouco condizentes com as condições brasileiras ou, ainda, são realizadas extrapolações de valores nutricionais constantes nas tabelas de exigências para frangos de corte, galinhas poedeiras e perus. Os aminoácidos sintéticos possuem baixo preço, por isso há uma crescente prática de se incorporá-los nas rações, permitindo que os teores de proteína bruta sejam inferiores ao recomendado nas tabelas de exigência em aminoácidos essenciais e assim diminuir o custo da ração. Há uma proporção adequada de aminoácidos limitantes para as codornas, e se não supridas de forma marginal, o ganho de peso e a conversão alimentar são 
DELLA-FLORA, R.P. et al. Exigências aminoacídicas para codornas. PUBVET, Londrina, V. 6, N. 30, Ed. 217, Art. 1444, 2012.

claramente afetados, por isso a importância de se conhecer a exigência de cada espécie de aves, não utilizando a formulação de outra para alimentá-las, para assim poder explorar ao máximo o seu potencial. Este trabalho teve por objetivo realizar uma revisão de literatura sobre este assunto.

Palavras-chave: aminoácidos; coturnicultura; nutrição.

\title{
Amino acid requirements for quails
}

\begin{abstract}
Due to the lack of scientific information on the amino acid requirements for Japanese quails (Coturnix coturnix japonica) and European ones (Coturnix coturnix coturnix), unsuitable charts of nutritional requirements regarding Brazilian conditions are often times used, such as NRC (1994) and INRA (1999), or even extrapolations are made for nutritional values listed in the charts of requirements for broiler chickens, laying hens and turkeys. Synthetic amino acids are reasonably cheap, so there is a growing practice of incorporating them in the feed, allowing crude protein levels to be lower than the recommended requirements in the charts of essential amino acids, thus reducing the cost of feed. There is a proper ratio of limiting amino acids for quails, which, if not supplied marginally, clearly affect weight gain and feed conversion. Therefore, it is important to understand the requirement of each species of birds, not using the formulation of another to feed them, so that their fullest potential can be explored. This study aimed to conduct a literature review on this subject.
\end{abstract}

Keywords: aminoacids; quail raising; nutrition.

\section{Introdução}

A coturnicultura vem se destacando no mercado agropecuário brasileiro como excelente atividade produtiva, por ter seus aspectos positivos da criação, principalmente por requerer baixo custo com investimento inicial e mão-de- 
DELLA-FLORA, R.P. et al. Exigências aminoacídicas para codornas. PUBVET, Londrina, V. 6, N. 30, Ed. 217, Art. 1444, 2012.

obra, utilizando pequenas áreas, fácil manejo e proporcionando rápido retorno de capital (SILVA et al., 2005).

O Brasil é o quinto maior produtor mundial de carne de codornas e o segundo de ovos. De 2005 para 2006, o alojamento cresceu 12,5\% nas diversas regiões do país, coincidindo com o surgimento das grandes criações e novas formas de comercialização do ovo e da carcaça de codornas.

Silva et al. (2009) afirmam ainda que a codorna é uma excelente alternativa para alimentação humana, pois pode ser utilizada tanto para a produção de ovos como para a produção de carne, que é aceita universalmente por ser um produto de excelente qualidade e rica em aminoácidos essenciais. Apresenta também alto conteúdo protéico e de aminoácidos e baixa quantidade de gordura, conforme observado na tabela 1 (CUNHA, 2009).

A alimentação afeta os custos de produção das codornas desde a base até o topo da cadeia produtiva, a indústria do melhoramento genético, os abatedouros e frigoríficos, desempenhando um papel fundamental na criação. Portanto, é indispensável administrar rações devidamente balanceadas, capazes de satisfazer às necessidades da ave e permitir seu perfeito desenvolvimento (MURAKAMI \& ARIKI, 1998). A ração representa cerca de 65 a $70 \%$ do custo de produção, sendo a proteína responsável por cerca de $25 \%$ deste custo. Em caso de erro na dosagem de nutrientes, especialmente os aminoácidos, este percentual pode ser ainda maior, podendo causar danos ao desempenho das aves pelo imbalanço, antagonismo e toxidez (SILVA \& RIBEIRO, 2001).

As codornas japonesas estão sendo melhoradas para alta produção de ovos mais nutritivos, de melhor qualidade e com menor teor de colesterol (MINVIELLE \& OGUZ, 2002), enquanto as codornas pesadas vêm sendo selecionadas para alta taxa de ganho nas primeiras quatro semanas (AGGREYET al., 2003). Portanto, novas pesquisas com codornas na área de 
DELLA-FLORA, R.P. et al. Exigências aminoacídicas para codornas. PUBVET, Londrina, V. 6, N. 30, Ed. 217, Art. 1444, 2012.

nutrição têm surgido na literatura nacional e internacional, a partir do início deste século.

\section{Exigências Nutricionais}

Vários autores têm se dedicado às pesquisas na área de nutrição e avaliação do conteúdo energético de alimentos para codornas (SAKAMOTO et al., 2006; SANTOS et al., 2006; GOMES et al., 2007; OLIVEIRA, 2007; SOARES et al., 2007; REZENDE et al., 2009), porém ainda há escassez de dados, principalmente em comparação aos obtidos com frangos e galinhas. A limitação dessas informações prejudica a elaboração de dietas para máxima lucratividade e desempenho na coturnicultura.

A tecnologia de formulação de rações é, praticamente, toda ela baseada em informações de composição de alimento e de exigências nutricionais estabelecidas no exterior, principalmente nos Estados Unidos e Europa (MURAKAMI, 1998, ROSTAGNO et al., 2000). Essas exigências nutricionais não são ideais em condições tropicais para a obtenção do máximo desempenho dessas espécies, principalmente, quando consideradas as condições climáticas brasileiras. A comparação dos resultados obtidos com codornas européias é ainda mais difícil, pois a maioria dos resultados encontrados refere-se a codornas japonesas (BARRETO et al., 2006).

Vários autores concluíram que a idade, sexo, linhagem, aminoácidos na dieta entre outros, podem interferir nas exigências de proteína bruta e energia metabolizável das codornas (MORAES \& ARIKI, 2009).. Esses fatores podem influenciar de forma diferente nas várias espécies de aves, devido às características anatômicas que as mesmas apresentam, em termos de tamanho e comprimento dos órgãos do trato gastrointestinal, particularidades fisiológicas e, às vezes, hábitos alimentares (MURAKAMI \& FURLAN, 2002). Também a qualidade da matéria prima é fundamental para exploração normal. Fatores anti-nutricionais, contaminações por outros grãos, fungos bactérias, com certeza, afetam a criação causando prejuízos à produção normal. 
DELLA-FLORA, R.P. et al. Exigências aminoacídicas para codornas. PUBVET, Londrina, V. 6, N. 30, Ed. 217, Art. 1444, 2012.

Para formular rações que permitam obter bons resultados zootécnicos a um custo mínimo é necessário conhecer a composição aminoacídica de cada ingrediente a ser utilizado. Muitos trabalhos científicos estão sendo desenvolvidos para estudar o valor nutritivo dos alimentos, o que resultam nas tabelas de referências, cada vez mais precisas e completas (FRAIHA, 2002).

Ainda hoje, as formulações das rações para codornas baseiam-se no conceito de proteína bruta (PB), o que resulta em dietas com o conteúdo aminoacídico superior ou inferior ao exigido, levando a alteração na produção e prejudicando o retorno econômico da atividade (ALBINO et al., 1992). O excesso de aminoácidos circulante no sangue pode provocar ainda a diminuição do consumo de ração pelos animais (GOULART, 1997). Com a possibilidade do uso de aminoácidos sintéticos nas dietas, tem sido possível formular dietas de custo mínimo e com teores de proteína bruta inferiores aos recomendados nas tabelas de exigências nutricionais, porém atendendo as exigências em aminoácidos essenciais (ARAÚjO et al., 2001; SILVA et al., 2005).

Silva et al. (2006) demonstraram que a suplementação com metionina de rações, cuja proteína foi reduzida em 20\% (28 para 22,4 \% de 1 a 21 e de 24 para $19,2 \%$ de 22 a 42 dias), promoveu conversão alimentar em codornas européias semelhante ao controle.

O excesso de proteína ou o desequilíbrio na relação entre os aminoácidos essenciais e os não-essenciais aumentam o catabolismo. Mais energia é desviada pelo organismo para sintetizar ácido úrico, aumentando a perda fecal de nitrogênio, tornado insuportável a qualidade do ambiente nas instalações mal manejadas e planejadas, podendo interferir na saúde do homem e das aves. 
DELLA-FLORA, R.P. et al. Exigências aminoacídicas para codornas. PUBVET, Londrina, V. 6, N. 30, Ed. 217, Art. 1444, 2012.

\section{Aminoácidos}

Diversos fatores parecem determinar o requerimento em aminoácidos, destacando-se o nível protéico e energético da ração, a qualidade da proteína, o tipo e a idade da ave. Para poedeiras leves, vários trabalhos têm indicado a possibilidade de se reduzir o nível protéico das rações, desde que devidamente suplementadas com os referidos aminoácidos (CARMO, 1981; BRAGA, 1984). De acordo com Schuhmacher et al. (1993), quando a lisina, a metionina e a cistina são supridas de forma marginal, o ganho de peso e a conversão alimentar são mais claramente alterados.

A nutrição de aminoácidos em aves tem sido objeto de estudos por décadas e a melhora da eficiência de utilização destes nutrientes continua sendo amplamente estudada, resultando em avanços significativos (FRAIHA, 2002). Em função das facilidades de compra e de preços compatíveis, atualmente há uma crescente prática de se incorporar aminoácidos sintéticos nas rações, permitindo obter rações de mínimo custo e com teores de proteína bruta inferiores aos recomendados nas tabelas de exigência em aminoácidos essenciais (CONHALATO, 1999). Com o fornecimento dos níveis de aminoácidos mais próximos das necessidades animais, há aumento na eficiência de utilização protéica e maximização do uso dos aminoácidos para síntese protéica, minimizando o seu uso como fonte de energia (PINTO et al., 2003).

A deficiência de aminoácidos pode resultar em aumento do consumo alimentar, para atender as necessidades diárias destes, também pode causar deposição desproporcional de tecido adiposo em relação à deposição muscular. A ligeira deficiência não irá refletir inicialmente nos resultados de ganho de peso, mas sim, no aumento da proporção de tecido adiposo dos animais, devendo ser uma das causas apontadas como fonte de obesidade em algumas espécies, como: frangos de corte, perus, patos e codornas (KLASING, 1994). 
DELLA-FLORA, R.P. et al. Exigências aminoacídicas para codornas. PUBVET, Londrina, V. 6, N. 30, Ed. 217, Art. 1444, 2012.

Torna-se difícil definir as exigências de aminoácidos para as aves sabendo-se que são influenciados pela expressão genética, densidade calórica da dieta, condições ambientais, densidade populacional, estado sanitário, etc. (ARAÚJO et al., 2001). Entretanto, estudos têm mostrado que quando se tem deficiência ou imbalanço de aminoácidos ocorrem reações variadas por parte das aves, promovendo alterações no consumo alimentar, pois o excesso de aminoácidos leva a diminuição do desempenho (TORRES et al., 2005).

Os aminoácidos têm várias funções no organismo e as necessidades de formar as proteínas corporais são, quantitativamente, prioritárias. Dos vinte aminoácidos que as codornas exigem apenas nove, são considerados essenciais (D'MELLO, 2003), e, destes, apenas as exigências de lisina e dos aminoácidos sulfurosos foram avaliadas na maioria dos estudos, enquanto, escassas pesquisas foram realizadas com treonina.

\section{Principais Aminoácidos para codornas.}

Metionina e lisina são os dois principais aminoácidos limitantes em aves e não são sintetizados em quantidade suficiente para sua utilização para máximo desempenho (BARRETO et al., 2006).

A lisina é considerada um aminoácido essencial às aves, porque é sintetizado no organismo em quantidade insuficiente para atender as necessidades destas. Além disso, é o segundo aminoácido limitante para elas, obrigando sua ingestão complementar na proteína intacta do alimento ou em fontes sintéticas como L-Lisina $\mathrm{HCl}$ (COSTA et al., 2001).

A estimativa das exigências em lisina pode ser o ponto de partida para a formulação de rações corretamente balanceadas, com base no conceito de proteína ideal, pois a lisina tem sido o aminoácido de referência no estabelecimento das exigências de proteína e de outros aminoácidos (BACKER \& HAN, 1994).O motivo da escolha é o fato de que a lisina é utilizada quase que exclusivamente para acréscimo de proteína corporal, não sendo 
DELLA-FLORA, R.P. et al. Exigências aminoacídicas para codornas. PUBVET, Londrina, V. 6, N. 30, Ed. 217, Art. 1444, 2012.

complicada por diferentes passos metabólicos para a manutenção ou plumagem (PACK, 1995). Isto significa que qualquer aminoácido pode se relacionar com a lisina (FIRMAN \& BOLING, 1998), de modo que, se houver alteração na sua exigência e/ou ambiente, conseqüentemente os outros aminoácidos também serão alterados (BACKER \& HAN, 1994).

Segundo Araújo et al. (2001), uma das funções mais importantes é sua participação na deposição de proteína corporal e na síntese de carnitina, que atua no transporte de ácidos graxos para a $\beta$-oxidação na mitocôndria, na formação da matriz óssea em animais jovens e no crescimento muscular (SILVA, 1997).

A lisina é o terceiro aminoácido mais tóxico para as aves (KOELKEBECECKET et al., 1991), o antagonismo lisina e arginina pode causar sintomas de deficiência de arginina devido a competição por sítios de absorção nos enterócitos (KIDD \& KERR, 1998). Entretanto, com a aplicação do conceito de proteína ideal, onde a lisina é o aminoácido de referência, mesmo se a exigência de lisina for alterada por fatores dietéticos, genéticos e ambientais, a relação ideal deve ser mantida.

Aves alimentadas com dietas em que a concentração de lisina é inferior às suas necessidades, reduzem o crescimento e apresentam menores ganhos de pesos, rendimentos de carcaças e piores índices produtivos. Por outro lado, tem sido constatado que concentrações excessivas de lisina na dieta podem produzir efeitos negativos sobre o desempenho e qualidade de carcaça das aves (LATSHAW, 1993).

A metionina é considerada aminoácido essencial para o crescimento das aves, por ser doadora de radicais metil, necessários à biossíntese de creatina, carnitina, poliaminas, epinefrina, colina e melatonina, que são componentes corporais fundamentais ao crescimento normal dos animais. Além disso, no organismo a metionina pode ser catabolisada à cistina, entretanto, esta conversão não é reversível, pois a cistina não pode ir a metionina e por isso 
DELLA-FLORA, R.P. et al. Exigências aminoacídicas para codornas. PUBVET, Londrina, V. 6, N. 30, Ed. 217, Art. 1444, 2012.

torna-se necessário determinar os níveis adequados destes aminoácidos, a fim de se atender esta inter-relação (BARBOSA, 1998).

Esse catabolismo tem funções de remover o excesso de metionina e superar a deficiência de cistina (GRABER et al., 1971). A cistina participa da estrutura de muitas proteínas, como insulina, imunoglobulinas e queratina, interligando cadeias polipeptídicas por ponte dissulfeto (BAKER, 1991).

A principio acreditava-se que a cistina fosse também aminoácido essencial, mas observações posteriores indicaram que é possível obtê-la de dieta onde não falta metionina.

Quando a cistina está presente há menor necessidade de conversão de metionina, o que economiza a quantidade deste aminoácido essencial na alimentação diária (TEIXEIRA, 1991), ou seja, a adição deste aminoácido em dietas com níveis marginais de metionina, reduz consideravelmente 0 complexo enzimático e a degradação da metionina, conservando-a para outras funções. Esse catabolismo sob condições normais, atinge duas funções: (1) remover o excesso de metionina, o qual é extremanente tóxico e (2) superar a deficiência de cistina (GRABER et al., 1971).

Outras funções da cistina são formação do piruvato e a utilização na síntese de vários compostos contendo enxofre, incluindo a taurina, aminoácido que participa na formação do ácido biliar, que é importante na digestão de lipídeos.

Segundo Baker et al.(1996), pode-se considerar a exigência de metionina digestível como $50 \%$ do valor da exigência da metionina+cistina digestível.

A metionina é o primeiro aminoácido limitante para aves que recebem dietas à base de milho e soja, ingredientes que compõem as dietas tradicionais de aves no Brasil. Tem-se também considerado que, no mínimo, 55\% dos aminoácidos sulfurosos na ração devem ser fornecidos na forma de metionina para as aves em todas as fases de criação (ROSTAGNO et al., 1996).

Segundo Wheller \& Latshaw (1981), quando se eleva o nível de metionina das dietas, ocorre aumento no peso corporal e diminuição no 
DELLA-FLORA, R.P. et al. Exigências aminoacídicas para codornas. PUBVET, Londrina, V. 6, N. 30, Ed. 217, Art. 1444, 2012.

consumo de dieta, contudo, quando as aves recebem dietas deficientes nesses aminoácidos, o contrário acontece, elevando, portanto, o consumo alimentar. Quanto maior o peso corporal, mais alimento será necessário para fornecer energia para mantença, restando pequena fração de energia para a síntese de proteína.

O fato dos aminoácidos serem constituídos das proteínas demonstra que suas necessidades diminuem com o avanço da idade. Entretanto, pesquisas sugerem que isso não acorre com os aminoácidos sulfurosos, pois a cistina é o aminoácido de maior concentração nas proteínas das penas, representando, portanto, o aumento de sua exigência, associado ao decréscimo de metionina com o avanço da idade das aves (GRABER et al, 1971). De acordo com Hartsook \& Mitchell (1956), essa relação é atribuída à queratina, que assume importante papel na síntese de proteína com o avanço da idade das aves.

Em dietas para aves à base de milho e farelo de soja, a treonina é o terceiro aminoácido limitante, precedido dos aminoácidos sulfurosos e da lisina. É exigido para formação da proteína e manutenção do turnover protéico corporal, além de auxiliar na formação do colágeno e da elastina e atuar na produção de anticorpos. A L-treonina pura é $100 \%$ digestível e está disponível comercialmente, oferecendo maior flexibilidade na formulação de dietas. Sua suplementação permite menor inclusão de alimentos protéicos, acarretando menores excreções de nitrogênio e poluição ambiental.

\section{Tabelas das exigências nutricionais}

Alguns estudos foram realizados no Brasil para estimar as exigências nutricionais de codornas européias e japonesas. Na Tabela 1, são apresentadas as especificações nutricionais para as fases de crescimento e de postura da codorna européia e na Tabela 2 para codornas japonesas. Em todas as fases, apesar da semelhança dos níveis de proteína e de energia recomendados na Tabela 2, para as codornas japonesas, os níveis dos aminoácidos são mais expressivos para codornas européias, influenciados, provavelmente, pela maior taxa de crescimento e maior peso corporal destas aves. 
DELLA-FLORA, R.P. et al. Exigências aminoacídicas para codornas. PUBVET, Londrina, V. 6, N. 30, Ed. 217, Art. 1444, 2012.

Tabela 1. Recomendações de aminoácidos para codornas européias em todas as idades

\begin{tabular}{llccccc}
\hline & \multicolumn{2}{c}{ Inicial (1 a 21d) } & \multicolumn{2}{c}{ Crescimento (22 a42d) } & \multicolumn{2}{c}{ Postura } \\
\hline Proteína bruta (\%) & \multicolumn{2}{c}{25} & \multicolumn{2}{c}{22} & \multicolumn{2}{c}{2.900} \\
\hline EMAn (Kcal/Kg) & \multicolumn{2}{c}{2.900} & \multicolumn{2}{c}{3.050} & Dotal & Dig. \\
\hline Aminoácidos (\%) & Total & Dig. & Total & 1,73 & 1,62 & 1,51 \\
\hline Arginina & 2,07 & 1,92 & 1,86 & 0,7 & 0,54 & 0,5 \\
Histina & 0,84 & 0,78 & 0,76 & 1,03 & 1,15 & 1,04 \\
Isoleucina & 1,25 & 1,14 & 1,12 & 1,24 & 0,99 & 0,91 \\
Fenialanina & 1,5 & 1,38 & 1,35 & 1,83 & 1,87 & 1,71 \\
Fenialanina+Tirosina & 2,22 & 2,03 & 2,00 & 2,17 & 1,82 & 1,72 \\
Leucina & 2,55 & 2,41 & 2,30 & 1,23 & 1,30 & 1,15 \\
Lisina & 1,56 & 1,37 & 1,40 & 0,50 & 0,50 & 0,46 \\
Metionina & 0,60 & 0,55 & 0,54 & 0,94 & 0,94 & 0,84 \\
Metionina+Cistina & 1,16 & 1,04 & 1,04 & 0,70 & 0,95 & 0,81 \\
treonina & 1,22 & 1,04 & 0,83 & 0,17 & 0,23 & 0,20 \\
Triptofano & 0,21 & 0,19 & 0,19 & 0,91 & 1,18 & 1,05 \\
Valina & 1,14 & 1,01 & 1,01 & &
\end{tabular}

Fonte: Silva e Costa (2009).;EMAn = energia metabolizável corrigida. Dig. = Digestivel

As percentagens de lisina total relativa à proteína foram de 6,$2 ; 5,3 ; 5,6$ e $6,5 \%$, respectivamente, para a fase inicial, crescimento, período total de crescimento e produção de ovos para as codornas europeias (Tabela I), enquanto para as codornas japonesas foram $5,4 \%$ em todas as fases desde 0 crescimento até a produção de ovos (considerando a recomendação para a postura 1). Portanto, as codornas européias tendem a exigir maiores quantidades de lisina em relação ao conteúdo de proteína da dieta. Novamente, a maior taxa de crescimento, especialmente, dos músculos peitorais nas codornas européias é a possível explicação para este resultado, devido à lisina ser quase exclusivamente utilizada para síntese de proteína corporal. Tendência semelhante foi constatada em frangos de linhagens modernas (de conformação) que exigem maior proporção de lisina na dieta em comparação com os níveis proteicos (ROSTAGNO et al., 2005). 
DELLA-FLORA, R.P. et al. Exigências aminoacídicas para codornas. PUBVET, Londrina, V. 6, N. 30, Ed. 217, Art. 1444, 2012.

Tabela 2. Recomendações de aminoácidos para codornas japonesas em todas as idades

\begin{tabular}{lcccccccc}
\hline Proteina Bruta (\%) & \multicolumn{2}{c}{$25(1 \mathrm{a} 21 \mathrm{~d})$} & \multicolumn{2}{c}{$22(22 \mathrm{a} \mathrm{42d)}$} & \multicolumn{2}{c}{20 (Postura1) } & \multicolumn{2}{c}{23 (Postura2) } \\
\hline EMAn (Kcal/Kg)) & \multicolumn{2}{c}{2.900} & \multicolumn{2}{c}{3.050} & \multicolumn{2}{c}{2.800} & \multicolumn{2}{c}{2.950} \\
\hline Aminoácidos (\%) & Total & Dig. & Total & Dig. & Total & Dig. & Total & Dig. \\
\hline Arginina & 1,25 & 1,16 & 1,13 & 1,05 & 1,35 & 1,26 & 1,48 & 1,38 \\
Histina & 0,36 & 0,33 & 0,3 & 0,28 & 0,45 & 0,42 & 0,49 & 0,46 \\
Isoleucina & 0,98 & 0,89 & 0,81 & 0,74 & 0,96 & 0,87 & 1,06 & 0,96 \\
Fenilalinina & 0,93 & 0,85 & 0,88 & 0,81 & 0,83 & 0,76 & 0,91 & 0,84 \\
Fenilalinina+treonina & 1,79 & 1,64 & 1,25 & 1,14 & 1,56 & 1,42 & 1,72 & 1,57 \\
Leucina & 1,69 & 1,60 & 1,28 & 1,21 & 1,52 & 1,43 & 1,67 & 1,58 \\
Lisina & 1,36 & 1,19 & 1,20 & 1,05 & 1,08 & 0,95 & 1,20 & 1,05 \\
Metionina & 0,50 & 0,46 & 0,45 & 0,41 & 0,42 & 0,39 & 0,46 & 0,42 \\
Metionina+Cistina & 0,90 & 0,80 & 0,83 & 0,74 & 0,78 & 0,70 & 0,80 & 0,72 \\
Treonina & 1,02 & 0,87 & 0,96 & 0,82 & 0,79 & 0,67 & 0,86 & 0,73 \\
Triptofano & 0,22 & 0,20 & 0,17 & 0,15 & 0,20 & 0,18 & 0,22 & 0,20 \\
Valina & 0,95 & 0,84 & 0,83 & 0,74 & 0,98 & 0,87 & 1,06 & 0,94 \\
\hline
\end{tabular}

Fonte: Silva e Costa (2009). EMAn = energia metabolizável corrigida. Dig. = Digestivel

Ribeiro et al. (2003) constataram que ao elevar o teor de proteína da ração de 20 para $23 \%$ a exigência de lisina passou de 1,07 para 1,15\%, respectivamente. A cada $1 \%$ de aumento no conteúdo de proteína da ração as exigências de lisina digestível e total aumentam 0,041 e 0,038\%; portanto, se uma ração é formulada com $20 \%$ de proteína são sugeridos, no mínimo, 1,08 e $0,95 \%$ e, com $23 \%$ de proteína, 1,20 e 1,05\%, respectivamente, de lisina total e digestível.

\section{Conclusão}

Pode-se concluir que as codornas pesadas exigem mais aminoácidos nas rações que as codornas melhoradas para a produção de ovos e, ambas, têm exigência aminoacídicas distintas daquelas de frangos e de galinha, portanto, rações formuladas para estas duas últimas espécies não devem ser fornecidas às codornas. 


\section{Revisão Bibliográfica}

AGGREY, S.E.; ANKRA-BADU, G.A.; MARKS, H.L. Effect of long-term divergent selection on growth characteristics in Japanese quail. Poultry Science, v.82, p.538-542, 2003.

ALBINO, L.F.T.; ROSTAGNO, H.S.; SANT'ANNA, R. et al. Determinação dos valores de aminoácidos metabolizável e proteína digestiva de alimentos para aves. Revista da Sociedade Brasileira de Zootecnia, v.21, n.6, p. 1059-1068, 1992.

ARAÚJO, L.F.; JUNQUEIRA, O.M.; ARAÚJO, C.S.S.N. et al. Proteína bruta e proteína ideal para frangos de corte no período de 1 a 21 dias de idade. Revista Brasileira de Ciência Avícola. Campinas. v.3, n.2, p. 1-10, 2001.

BACKER, D.H.; HAN, Y. Ideal amino acid profile for chickens during the first three weeks posthatching. Poultry Science, v.73, p. 1441-1447, 1994.

BAKER, D.H. Partitioning of nutrients for growth and other metabolic functions. Poultry Science, v.70, p.1797-1805, 1991.

BAKER, D.H.; FERNADEZ, S.R.; WEBEL, D.M. et al. Sulfur amino acid requirement and cystine replacement value of broiler chicks during the period three to six weeks posthatching. Poultry Science. V.75,p.737-742,1996

BARBOSA, R.J Exigência de metionina + cistina para frangos de corte na fase de crescimento e acabamento. Viçosa, MG: Universidade Federal de Viçosa, 1998. 84p. Dissertação (Mestrado em Zootecnia) - Universidade Federal de Viçosa, 1998.

BARRETO, S.L.T.; ARAUJO, M.S.; UMIGI, R.T. et al. Exigência nutricional de lisina para codornas européias machos de 21 a 49 dias de idade. Revista Brasileira de Zootecnia, v.35, n.3, p. 750-753, 2006.

BRAGA, D.F. Exigências nutricionais de lisina e aminoácidos sulfurosos para galinhas poedeiras e de lisina para em crescimento. Viçosa, MG, UFV, 1984. p.186. Tese (Doutorado em Zootecnia) - Universidade Federal de Viçosa, 1984.

CARMO, M.B. Níveis de proteína e aminoácidos sulfurosos em rações de galinhas poedeiras sob regime de alta temperatura.Viçosa, MG, UFV, 1984. p.104. Dissertação (Mestrado em Zootecnia) - Universidade Federal de Viçosa, 1981.

CONHALATO, G.S. Exigência de lisina digestível para frangos de corte machos na fase de 22 a 42 dias de idade. Revista Brasileira de Zootecnia, v.28, n.1, p. 98-104, 1999.

COSTA, F.G.P.; ROSTAGNO, H.S.; ALBINO, L.F.T. et al. Níveis de lisina digestível para frangos de corte machos na fase de 21 a 42 dias de idade. Revista Brasileira de Zootecnia, v.30, p.1490-1497, 2001.

CUNHA, F.S.A. Avaliação da mandioca (Manihot esculenta Crantz) e subprodutos na alimentação de codornas (Coturnix Japonica). Tese (Doutorado integrado em Zootecnia) - Universidade Federal Rural de Pernambuco. Universidade Federal da Paraíba. Universidade Federal do Ceará, Pernambuco, 2009.

D'MELO, J.P.F. Amino acids in animal nutrition. 2nd ed., CABI Publishing, Wallingford, 2003. 546p.

FIRMAN, J.D.; BOLING, S.D. Ideal protein in turkeys. Poultry Science, v.77, n.1, p.105-110, 1998. 
FRAIHA, M. Atualização em nutrição protéica para frangos de corte, 2002. Disponível em :<http://www.lisina.com.br/nutrição/palestra.asp.> Acesso em: 20 de abril 2012.

GOMES, F.U.; FASSANI, E.J.; RODRIGUES, P.B. et al. Valores energéticos de alguns alimentos utilizados em rações para codornas japonesas. Revista Brasileira de Zootecnia, v.36, n.2, p.396-402, 2007.

GOULART, C.C. Exigência nutricional de lisina para poedeiras leves e semipesadas. Viçosa, MG: Universidade Federal de Viçosa, 1997. 51p. Dissertação (Mestrado em Zootecnia) - Universidade Federal de Viçosa, 1997.

GRABER, H.G.; SCOTT, H.M.; BACKER D.H. Sulfuramino acid nutrition of the growing chick: Effect of age on the dietary methinine requirement. Poultry. Science., v.50, p 854-858, 1971.

HARTSOOK, E.W.; MITCHELL, H.H. The effect of age on the protein and methionine requirements of the rat. J. Nutr., v. 60, p. 173-195, 1956.

INSTITUTO NACIONAL DE LA RECHERCHE AGRONOMIQUE - INRA. Alimentação dos animais domésticos: suínos, coelhos e aves. 2. ed. São Paulo: Roca, 1999. 245p.

KIDD, M.T.; KERR, B.J. Dietary arginine and lysine ratios in large white toms. 2. Lack interaction between arginine: lysine ratios and electrolyte balance. Poultry Science, v.77, p.864-869, 1998.

KLASING, K. C. Comparative avian nutrition. CAB International, p. 350, 1994.

KOELKEBECK, K.W.; BAKER, D.H.; HAN, Y. Research note: effect of excess lysine, methionine, threonine, or tryptophan on production performance of laying hens. Poultry Science, v.70, pl1651-1653, 1991.

LATSHAW, J.D. Dietary lysine concentrations from deficient to excessive and the effects of broiler chicks. Br. Poultry Science, v.34, p. 951-958, 1993.

MINVIELLE, F.; OGUZ, Y. Effect of genetics and breeding on egg quality of Japanese quail.World's Poultry Science, v.58, p.291-295. 2002.

MORAES, V.M.B.; ARIKI, J. Importância da nutrição na criação de codornas de qualidades nutricionais do ovo e carne de codorna. Universidade Estadual Paulista, Jaboticabal-SP, p.97-103, 2009. Disponível em: www.biologico.sp.gov.br/rifibi/IIIrifibi/97103.pdf Acesso em: 6 mar. 2012.

MURAKAMI, A.E. Nutrição e alimentação de codornas em postura. In: Simpósio Sobre Nutrição e Tecnologia da Produção de Rações. Anais... Campinas, Sp. P.19-38, 1998.

MURAKAMI, A.E.; ARIKI, J. Produção de codornas japonesas. Jaboticabal: FUNEP, 1998. 79p.

MURAKAMI, A.E.; FURLAN, A.C. Pesquisas na nutrição e alimentação de codornas em postura no Brasil. In: SIMPÓSIO INTERNACIONAL COTURNICULTURA, 1., 2002, Lavras. Anais..., Lavras:Universidade Federal de Lavras/NECTA, [2002]. CD-ROM. Palestra, p.1-5.

NATIONAL RESEARCH COUNCIL (NRC). Nutrient requirements of poultry. 9 ed., Washington. D.C.: National Academic Press, 1994. p. 44-45.

OLIVEIRA, B.L. Manejo em granjas automatizadas de codornas de postura comercial. In: SIMPÓSIO INTERNACIONAL, 3.; CONGRESSO BRASILEIRO DE COTURNICULTURA, 2., 2007, Lavras. Anais... Lavras: Universidade Federal de Lavras, 2007. p.11-16. 
PACK, M. Proteína ideal para frangos de corte. Conceito atual. In: CONFERÊNCIA APINCO DE CIÊNCIA E TECNOLOGIA AVÍCOLAS, 1995, Curitiba. Anais... Campinas: Fundação Apinco de Ciência e Tecnologia Avícolas, 1995, p. 95-110.

PINTO, R.; DONZELE, J.L.; FERREIRA, A.S. et al. Exigência de metionina mais cistina para codornas japonesas em postura. Revista Brasileira de Zootecnia, v.32, n.5, p. 1166-1173, 2003.

REZENDE, M.J.M.; TORRES, A.F.; MURATA, L.S. et al. Determination of metabolizable energy value of corn with different average geometric diameters for european quails (Coturnix coturnix coturnix) Brazilian Archives of Biology and Technology, v.52, n.4, p.981-984, 2009.

RIBEIRO, M.L.G.; SILVA, J.H.V.; DANTAS, M.O. et al. Exigências nutricionais de lisina para codornas durante a fase de produção em função do nível de proteína da ração. Viçosa.

Revista Brasileira de Zootecnia, v.32, n.01. p.156-161, 2003.

ROSTAGNO, H.S., ALBINO, L.F.T., DONZELE, J.L. et al. Tabelas brasileiras para suínos e aves. Composição de alimentos e exigências nutricionais. Editor Rostagno, H.S. Viçosa: UFV, Departamento de Zootecnia, 2000, 141p.

ROSTAGNO, H.S., ALBINO, L.F.T, DONZELE, J.L. et al. Tabelas brasileiras para aves e suínos (Composição de alimentos e exigências nutricionais). $2^{a}$ ed., Viçosa, MG: UFV, Departamento de Zootecnia, 2005. 186p.

ROSTAGNO, H.S.; BARBARINO JR., P.; BARBOSA, W.A. Exigências nutricionais das aves determinadas no Brasil. In: SIMPÓSIO INTERNACIONAL SOBRE EXIGÊNCIAS NUTRICIONAIS DE AVES E SUÍNOS, Viçosa, MG, 1996. Anais... Viçosa, MG: Universidade Federal de Viçosa, 1996, p.361-388.

SAKAMOTO, M.I.; MURAKAMI, A.E.; SOUZA, L.M.G. et al. Valor energético de alguns alimentos alternativos para codornas japonesas. Revista Brasileira de Zootecnia, v.35, n.3, p.818821, 2006.

SANTOS, A.L.S.; GOMES, A.V.C.; PESSOA, M.F. et al. Composição química e valores energéticos de fontes protéicas em codornas de corte em diferentes idades. Revista Ciência Rural, v.36, n.3, p.930-935, 2006.

SCHUHMACHER, A., EISSNER, C., GROPP, J.M. et al. Carnitine in fish, piglets and quail. In: VITAMINE UND WEITERE ZUSATZSTOFFE BEI MENSCH UND TIER, 4, 1993. Proceedings... p.407-412, 1993.

SILVA, E.L.; SILVA, J.H.V.; JORDÃO FILHO, J. et al. Redução dos níveis de proteína e suplementação aminoacídica em rações para codornas européias (Coturnix coturnix coturnix). Revista Brasileira de Zootecnia. v.35. n.3, p. 822-829, 2006.

SILVA, J.H.V.; COSTA, F.G.P. Tabela para codornas japonesas e européias. $2^{a}$ ed., Ed. FUNEP, Jaboticabal, SP, 110p, 2009.

SILVA, J.H.V.; RIBEIRO, M.L.G. Tabela nacional de exigência nutricional de codornas (Coturnix coturnix japonica). Bananeiras, PB:DAP/UFPB/Campus IV, 2001, 19p.

SILVA, M.A.; CORRÊA, G.S.S.; CORRÊA, A.B. et al. Exigência de metionina + cistina para codornas de corte durante a fase inicial (sete a 21 dias). In: REUNIÃO ANUAL DA SOCIEDADE BRASILEIRA DE ZOOTECNIA, 42., 2005, Goiânia. Anais... Goiânia: Sociedade Brasileira de Zootecnia/Gmosis, [2005]. CD-ROM. Nutrição de Não ruminantes. NNR-1135. 
SILVA, R.M.; FURLAN, A.C.; TON, A.P.S. et al. Exigências nutricionais de cálcio e fósforo de codornas de corte em crescimento. Revista Brasileira de Zootecnia, v. 38 , n . 8 , p. 1509 - 1517, 2009.

SILVA, S.H.M. Exigência em metionina+cistina para duas marcas comerciais de frangos de corte. Viçosa, MG: Universidade Federal de Viçosa, 1997. 52p. Dissertação (Mestrado em Zootecnia) - Universidade Federal de Viçosa, 1997.

SOARES, M.B.; FUENTE, F.M.F.; FREITAS, E.R. et al. Farelo de amêndoa da castanha de caju na alimentação de codornas japonesas na fase de postura. Revista Brasileira de Zootecnia, v.36, n.4, p.1076-1082, 2007.

TEIXEIRA, A.S. Alimentos e Alimentação. ESAL-FAEPE,1991.357p.

TORRES, R.A.; CORRÊA, G.S.S.; SILVA, M.A. et al. Desempenho de codornas EV2 para corte alimentadas com dietas com diferentes níveis de metionina+cistina durante a fase inicial. In: REUNIÃO ANUAL DA SOCIEDADE BRASILEIRA DE ZOOTECNIA, 42., 2005, Goiânia. Anais... Goiânia: Sociedade Brasileira de Zootecnia/Gmosis, [2005]. CD-ROM. Nutrição de Não ruminantes. NNR-1160.

WHEELER, K. B.; LATSHAW, J. D. Sulfur amino acid requirement and interactions in broilers during two growth periods. Poultry Science, v. 60, p. 228-236, 1981. 